\title{
Therapeutic management of severe hypothermia with veno-arterial ECMO: where do we stand? Case report and review of the current literature
}

\author{
Aurélien Ledoux and Piehr Saint Leger
}

\begin{abstract}
Background: Severe accidental hypothermia is associated with high morbidity and mortality. Veno-arterial extracorporeal membrane oxygenation (VA-ECMO) provides an efficient rewarming method with complete cardiopulmonary support. The use of VA-ECMO for this indication has greatly improved the vital and functional prognosis of patients.

Case presentation: We report a case of a 46-year-old patient who was treated for severe hypothermia with a temperature of $22.4^{\circ} \mathrm{C}$ along with initial cardiac arrest, whose progression was favorable after the implementation of VA-ECMO support. Two months after initial cardiac arrest, the patient was reassessed and showed signs of complete recovery with regard to his mental and physical capacities.

Conclusions: The recent international publications and groups of experts recommend the use of VA ECMO as the gold standard therapy to treat severe hypothermia. Therefore, it seems suitable to update the current knowledge on the topic by analysing the latest international publications. The performance of this technique calls into question ethical and economic factors. Two distinct medical teams tried to identify and regroup prognosis factors in predictive survival scores. They raise the question of the utility of these scores in clinical practice. Indeed, according to which survival rate should we proceed to prolonged resuscitation and implement VA-ECMO? Additional studies will be needed for external approval of these survival scores, and additional reflection by experts will be required.
\end{abstract}

Keywords: Hypothermia, Cardiac arrest, Extracorporeal membrane oxygenation, Rewarming

\section{Introduction}

Severe accidental hypothermia is defined as a core body temperature below or equal to $28^{\circ} \mathrm{C}$ corresponding to hypothermia degree III (HT III) and IV (HT IV) in the Swiss staging model of the international classification of accidental hypothermia, presented in Table 1 [1]. In these hypothermia, HT III and HT IV, severe hemodynamic instability can lead to cardiac arrest, with increased

\footnotetext{
* Correspondence: saintleger-p@ch-valenciennes.fr Department of Intensive Care Medicine, General Hospital of Valenciennes, Valenciennes, France
}

mortality from deeper hypothermia, but no percentage of mortality exists in the literature.

The treatment in these indications are based on active internal warming by extracorporeal life support (ECLS) with the use of vein-arterial ECMO (VA-ECMO) which is increasingly recommended as the preferred method due to its rapid availability, lower heparinization requirement and possibility of prolonged support $[2,3]$.

First, we will describe a case study of a positive outcome of a patient who was treated for HT IV with early VA ECMO. Then, we will explore and review the

\section{$\triangle B M C$}

(c) The Author(s). 2020 Open Access This article is licensed under a Creative Commons Attribution 4.0 International License, which permits use, sharing, adaptation, distribution and reproduction in any medium or format, as long as you give appropriate credit to the original author(s) and the source, provide a link to the Creative Commons licence, and indicate if changes were made. The images or other third party material in this article are included in the article's Creative Commons licence, unless indicated otherwise in a credit line to the material. If material is not included in the article's Creative Commons licence and your intended use is not permitted by statutory regulation or exceeds the permitted use, you will need to obtain permission directly from the copyright holder. To view a copy of this licence, visit http://creativecommons.org/licenses/by/4.0/ The Creative Commons Public Domain Dedication waiver (http://creativecommons.org/publicdomain/zero/1.0/) applies to the data made available in this article, unless otherwise stated in a credit line to the data. 
Table 1 Swiss clinical staging of hypothermia [1]

\begin{tabular}{lll}
\hline Stage & Clinical symptoms & $\begin{array}{l}\text { Typical core } \\
\text { temperature }\left({ }^{\circ} \mathrm{C}\right)\end{array}$ \\
\hline Hypothermia & Conscious, shivering & $35-32^{\circ} \mathrm{C}$ \\
$\begin{array}{l}\text { Hypothermia } \\
\text { II }\end{array}$ & $\begin{array}{l}\text { Impaired consciousness, no } \\
\text { shivering }\end{array}$ & $32-28^{\circ} \mathrm{C}$ \\
$\begin{array}{l}\text { Hypothermia } \\
\text { III }\end{array}$ & $\begin{array}{l}\text { Unconscious, no shivering, vitals } \\
\text { signs present }\end{array}$ & $28-24^{\circ} \mathrm{C}$ \\
$\begin{array}{l}\text { Hypothermia } \\
\text { IV }\end{array}$ & No or minimal vital signs & $<24^{\circ} \mathrm{C}$ \\
\hline
\end{tabular}

available literature, discuss it and, finally, propose some recommendations.

\section{Report}

A 46-year-old male was found in the street during winter in a calm areactive coma. The man was still breathing, but his core body temperature was $22.4^{\circ} \mathrm{C}$. The patient presented cardiovascular instability due to ventricular fibrillation during secure mobilization and was eligible for cardiopulmonary resuscitation (CPR). Return of spontaneous circulation (ROSC) occured after $45 \mathrm{~min}$ of cardiac massage, 7 external electric shocks and $10 \mathrm{mg}$ of intravascular epinephrine. Bradycardia remained at 30 beats per minute, leading to severe hypotension, bilateral mydriasis and Glasgow score of 3. He received no sedative medicine.

The initial balance sheet showed severe acidosis with a $\mathrm{pH}$ level of 6.98 combined with hyperlactatemia of 14.2 $\mathrm{mmol} / \mathrm{L}$. The serum potassium level was $4 \mathrm{mmol} / \mathrm{L}$. Disseminated intravascular coagulation was observed with a prothrombin ratio of $54 \%$, fibrin monomers at $122 \mu \mathrm{g} / \mathrm{ml}$ and D-Dimers at $15,1 \mathrm{mg} / \mathrm{L}$. Liver function tests were abnormal, with AST 25-times higher than normal. Rhabdomyolysis was observed at CPK $6.700 \mathrm{U} / \mathrm{L}$. Troponin at 0 , $029 \mu \mathrm{g} / \mathrm{l}$ was in the normal range $(N<0,04 \mu \mathrm{g} / \mathrm{L})$. Kidney function was disturbed, evidenced by a creatinine concentration of $244 \mu \mathrm{mol} / \mathrm{L}$.

The decision to apply extracorporeal life support (ECLS) was based on the following criteria: severity of core hypothermia, range of serum potassium level and occurrence of witnessed cardiac arrest with immediate successful CPR. Femoro-femoral VA-ECMO was performed in the ward upon arrival in order to provide active rewarming and circulatory support. The time from initial cardiopulmonary arrest to functional VA-ECMO was approximately $260 \mathrm{~min}$. The sweep gas flow and ECMO$\mathrm{FiO}_{2}$ were adjusted based on arterial blood gas analysis.

Return to a core body temperature above $36^{\circ} \mathrm{C}$ occured within 40 min of VA-ECMO implementation. There were no cardiac-related complications under VA-ECMO. Cardiac function was assessed by echocardiography, and no systolic dysfunction was reported on day 2. Left ventricular ejection fraction (LVEF) was 55\%, and subaortic velocity time integral (VTI) was $19 \mathrm{~cm} / \mathrm{s}$. VAECMO withdrawal was reviewed and performed on day 2 .

The patient stopped receiving sedatives on day 4 in order to perform neurologic evaluation. The patient presented generalized myoclonic seizures. Symptomatic treatment was achieved by levetiracetam after magnetic resonance imaging of the head revealed a minor postanoxic injury. During his recovery, the patient acquired ventilator-associated pneumonia, documented by Pseudomonas aeruginosa infection, which delayed extubation to day 17 . There was progressive recovery of renal function without the requirement of renal replacement therapy.

On day 26, the patient was transferred to the respiratory rehabilitation treatment. The patient was discharged from the hospital on day 40.

The patient was reassessed 2 months after the initial report. Clinical examination revealed a fully conscious and oriented patient, with disappearance of myoclonic seizures. He was able to walk without any help. Functional respiratory tests did not reveal any sequelae. Control echocardiography was performed, and the results showed a LVEF of $60 \%$ without any diastolic dysfunction.

\section{Discussion and literature review}

Severe hypothermia has multiple pathophysiological consequences within the organism, mostly affecting the cardiovascular system (heart conduction system, sinus bradycardia, long QT, J Osborne wave, ventricular fibrillation, severe hypotension due to vasoplegia and decreased cardiac output) [4-7], but also other systems such as the respiratory, cerebral or metabolic systems. All of these disorders lead to death of the patient as a result of cardiac or respiratory arrest, unless adequate treatment is provided.

HT III and HT IV treatment is based on warming the patient in order to restore homeostasis of the different systems and internal organs. In these cases, ECLS, which replaces the function of the heart by a pump and the function of the lungs by an oxygenation membrane, with a control of the temperature of the circuit, is the only recommended device to provide active internal warming $[1,2]$. Without any active internal warming, active external warming techniques are not used due to the risks associated with low cardiac output caused by peripheral vasodilatation. When ECLS is not available, other active internal warming techniques should be considered, such as peritoneal lavage, intravascular warming catheter and renal replacement therapy (intermittent or continuous) $[2,3]$.

Among the available ECLS devices, central or peripheral cardiopulmonary bypass (CPB) was the first replacement technique used in the early 1980s, with several 
conclusive publications on the topic. In particular, Althaus et al. reported full recovery of 3 patients after hypothermic cardio-respiratory arrest. One of the patients underwent active central warming by a central shunt, whereas the other two patients had a peripheral shunt with a femoro-femoral approach [8]. Since the early 2000s VA-ECMO has been the gold standard therapy for this indication [6, 7]. Compared to central cardio-pulmonary shunt, VA-ECMO remains a faster and easier supportive treatment to implement. Moreover, it requires less anticoagulation to function and has the ability to be maintained in place for effective support in the event of persistent cardiac instability or severe pulmonary oedema after rewarming. Ruttmann et al. demonstrated this use in a retrospective series of 59 patients with severe hypothermia with cardio-circulatory arrest at admission. Despite a high mortality rate of approximately $79 \%$ in this cohort, this high rate could be explained by failure to recover spontaneous cardiac activity during extracorporeal warming in 26 patients. The authors showed an increased in mortality in the group of patients rewarmed by the cardiopulmonary shunt without VA-ECMO. Thus, in the 33 patients with ROSC, the survival rate with a good neurological outcome was approximately $56 \%$ in patients with VAECMO, compared to $18 \%$ in patients with extracorporeal circulation (ECC). Moreover, the authors reported 9 deaths from massive pulmonary oedema in the ECC group, while there were no deaths in the VA-ECMO group. This study shows an increased mortality rate in the ECC group supported by the multivariate analysis. Indeed, VA-ECMO support was demonstrated as an independent risk factor of survival with an odds ratio (OR) of 6,6. The mechanisms underlying this increase in mortality rate can be explained by the occurrence of severe diastolic dysfunction of the left ventricle during rewarming and by ischemia-reperfusion injury. VAECMO, by giving the opportunity to provide prolonged hemodynamic support, could prevent this acute failure
[9]. The results of this study and the others discussed below are presented in Table 2 .

This post-rewarming heart failure was found in various studies with different results. In experimental studies on canine or pig models, residual left systolic ventricular dysfunction was demonstrated [14, 15]. However, in a more recent prospective work conducted on a small sample of 9 patients in which VA-ECMO was implemented for HT III or IV, the researchers discovered moderate biventricular diastolic dysfunction but no systolic impairment after the rewarming process [16].

In our case-report, there was no reported cardiac systolic or diastolic dysfunction in the control echocardiography performed on day 2 after the rewarming process. The cardiac sequelae do not seem to be systematic. The mechanisms and the various forms of injuries still remain to be confirmed by a study on larger sample group.

There are no defined international guidelines concerning rewarming rate after VA-ECMO implementation. More studies on the neurological clinical evolution of patients who underwent a rewarming process must be carried out, in particular, with regard to the rate of the rewarming process. Only two experimental studies have reported central neurological sequelae in the event of abrupt rewarming in profound hypothermia. These studies used extremely rapid rewarming models, such as $12{ }^{\circ} \mathrm{C}$ in $4 \mathrm{~min}$ in the work of Enomoto et al., which was conducted on rabbits, and $20^{\circ} \mathrm{C}$ in $20 \mathrm{~min}$ in a murine model in a study conducted by Gordan et al. $[17,18]$.

ECLS for HT IV patient is able to substantially improve survival rate by 21 to $100 \%$ according to the literature. Above all, there is a trend of an improved survival rate when VA-ECMO is the implemented ECLS mechanism $[9,19]$. In a recent literature review on ECLS and HT IV patients, researchers found a global survival rate of $73 \%$, with $89 \%$ of these patients showing a promising neurological recovery i.e., Cerebral Performance Category (CPC) 1 or 2 [20]. In this group, the researchers decided to only consider bystander-witnessed cardiac

Table 2 Studies presented in discussion who compared results of ECLS

\begin{tabular}{|c|c|c|c|c|}
\hline Studies & Type of study & Number of Patients & ECLS & $\begin{array}{l}\text { Survival with good } \\
\text { neurological outcome (\%) }\end{array}$ \\
\hline Althaus et al. [8] & Cases report & 3 & $3 \mathrm{CPB}$ & $3(100)$ \\
\hline Ruttman et al. [9] & Retrospective cohort & 59 & $\begin{array}{l}25 \text { VA ECMO } \\
34 \mathrm{CPB}\end{array}$ & $\begin{array}{l}9(36) \\
3(9)\end{array}$ \\
\hline Kosiński et al. [10] & Retrospective cohort & 31 & 31 VA ECMO & $16(52)$ \\
\hline Mair et al. [11] & Retrospective cohort & 22 & $22 \mathrm{CPB}$ & $2(9)$ \\
\hline Pasquier et al. [12] & Review of literature & 286 & $\begin{array}{l}85 \text { VA ECMO } \\
201 \text { CPB }\end{array}$ & $\begin{array}{l}36(42) \\
70(35)\end{array}$ \\
\hline Saczkowski et al. [13] & Review of literature & 658 & $\begin{array}{l}290 \text { VA ECMO } \\
368 \text { CPB }\end{array}$ & $\begin{array}{l}144(50) \\
121(33)\end{array}$ \\
\hline
\end{tabular}


arrest patients, especially during the initial mobilization. This made it possible to eliminate patients already in cardiac arrest at the initial management, and for whom it is difficult to know whether the cardiac arrest is induced by the profound hypothermia or due to a hypoxic cause, which makes the global prognosis poorer. Despite the retrospectivity bias, this analysis demonstrates the good outcome of early management of profound hypothermia by ECLS, even in the case of early-stage cardiac arrest.

These high survival rates with good neurological outcomes, even in the case of prolonged resuscitation, are thanks to the massive decrease in cerebral metabolism during deep hypothermia. The cerebral metabolic rate of oxygen is reduced by $6 \%$ for each $1{ }^{\circ} \mathrm{C}$ decrease in core body temperature. This allows the brain cells to tolerate circulatory arrests 10-times longer than usual [21].

In a retrospective trial involving 31 patients, the delay of cardio-pulmonary resuscitation before implementing VA-ECMO ranged from 107 to $345 \mathrm{~min}$, with 16 survivors, all of whom showed good neurological outcome (CPC1 or 2) [10]. For our patient, the time needed to implement VA-ECMO was approximately $260 \mathrm{~min}$ from the initial management and the start of the supportive circulatory treatment (low-flow time with CPR and external heart massage was $45 \mathrm{~min}$ ), which did not prevent a full neurological recovery.

However, is it truly necessary to implement ECLS with every patient with severe hypothermia? The post-hoc analysis of resuscitation failures and deaths among these patients identified a number of independent risk factors.

Of these risk factors, kalaemia seems to be the most relevant. Considerable hyperkalaemia is related to a worse outcome due to a supposed underlying prolonged hypoxia/anoxia, which results in ischemia and cell lysis. International guidelines recommend proceeding to resuscitation and implementing VA-ECMO when there is a serum potassium level lower than $12 \mathrm{mmol} / \mathrm{L}$, with an exception for avalanche hypothermia, where the cut-off value is $8 \mathrm{mmol} / \mathrm{L}$. In this specific case, there is a higher risk of asphyxia and hypoxia before circulatory arrest, which jeopardizes the prognosis $[1,6]$. These cut-off values are primarily based on published cases with good survival rate and neurological outcomes [22, 23].

Other parameters have been selected by the European Resuscitation Council to evaluate the futility of resuscitation in the case of HT III or HT IV, e.g., the concomitant presence of severe head injury, cerebral haemorrhage and/ or significant comorbidities [6]. Some studies suggest that the level of initial lactate or $\mathrm{pH}$ as a poor prognosis factor, but these parameters were not selected by the group of experts because of the lack of evidence in other published cohorts [11, 24]. Favourable and adverse prognosis factors are presented in Table 3.
Table 3 Favorable and adverse prognostic factors in the literature for deep hypothermia resuscitation

\begin{tabular}{ll}
\hline Favorable factor & Adverse factor \\
\hline Kalemia $<8 \mathrm{mmol}$ per liter & Kalemia $>12 \mathrm{mmol}$ per liter \\
No cardiac arrest associated & Asystole \\
Female & Male \\
& Severe head injury concomitant \\
& High comorbidity \\
& Cerebral hemorrhage associated \\
& Initial pH \\
& Initial lactate \\
\hline
\end{tabular}

More recently, two distinct medical teams tried to identify and regroup prognostic factors for good neurological outcome in predictive survival scores. Based on a retrospective analysis of 286 patients in 18 publications, Pasquier et al. developed the HOPE score, which takes into account six clinico-biological variables who are age, gender, asphyxia associated, CPR duration, serum potassium level and temperature (score calculation and predicted survival use an algorithm which is available online at: www.hypothermiascore.org). The statistical analysis showed that the area under the ROC curve for the HOPE score is more useful than kalaemia for predicting survival [12]. Saczkowski et al. published an another review screening 658 patients from 40 clinical cases and 44 retrospective cohorts. The survival rate was approximately $46 \%$, with a good neurological outcome rate of $87,5 \%$ among the survivors (CPC 1 or 2). Three independent risk factors were identified in these cohorts: the initial hyperkalaemia and previous asphyxia before cardiac arrest were related to poor prognosis, whereas female sex was related to better prognosis. On the basis of these three variables, they defined the ICE score to determinate a survival with good neurological prognosis, which ranges from 85 to $0 \%$ in this model. Correlated to an area under the ROC curve of 0,849 [13]. Components of these two scores are presented in Table 4. Limiting factors for HOPE and ICE scores exist, as there has not yet been external validation, and potential publication bias is possible.

In our case, the initial serum potassium level was 4 $\mathrm{mmol} / \mathrm{L}$, which is significantly below the $12 \mathrm{mmol} / \mathrm{L}$ cutoff. However, the lactate level was high, and the $\mathrm{pH}$ was below 7, which did not prevent good clinical and neurological outcomes. HOPE and ICE scores were not available when we managed our patient but if we calculated

Table 4 Components of the HOPE Score and ICE Score

\begin{tabular}{ll}
\hline HOPE Score [12] & ICE Score [13] \\
\hline Gender & Gender \\
Asphyxiation with hypothermia & Asphyxiation with hypothermia \\
First serum potassium & First serum potassium \\
Age & \\
Cardiopulmonary resuscitation duration & \\
Core temperature at admission & \\
\hline
\end{tabular}


them, the HOPE score resulted in 59\% survival, and the ICE score was 0 ( 0 point for male sex, 0 point for no associated asphyxia and 0 point for the initial serum potassium concentration less than $5 \mathrm{mmol} / \mathrm{l}$ ), corresponding to a probability of survival with a good neurological outcome of $60 \%[12,13]$. These results, similar for the two predictive scores, raise the question of their usefulness in clinical practice. Indeed, is there any existing survival score that can help us predict when to proceed to a prolonged resuscitation and implement VA-ECMO? The dilemma is then to counterbalance the predicted low survival rate against the cost of VA-ECMO implementation, and therefore, assess life-limit on a strictly economic basis. On the other hand, is there still an indication to implement such an expensive technique even if predictive scores show low survival rates under 60 or $70 \%$ ? These questions raise moral and economic questions and will require a reflection process, but first we need studies to approve these survival scores, and also to confirm the place of VA-ECMO in deep hypothermia. The development of new ECMO circuits that are easy to install and start will also be important in the years to come in order to make this technique more accessible and less expensive. Nevertheless, patients, after that ECMO is implanted, should be managed by an ICU expert team of a referral hospital [25].

\section{Conclusion}

Accidental severe hypothermia is a pathology with a high risk of cardiovascular collapse. However, with appropriate initial resuscitation, patients present good neurological outcomes. The studies reveal that VAECMO circulatory support seems to be the benchmark treatment to take over central rewarming in the international recommendations. Medical teams need to become aware of this less well-known treatment. However, scientifically speaking, we still need to develop some tools to identify patients eligible for this technique and balance the economic and medical limitations.

\section{Abbreviations \\ CPB: Cardiopulmonary Bypass; CPC: Cerebral Performance Category; CPR: Cardiopulmonary Resuscitation; ECC: Extracorporeal Circulation; ECLS: Extracorporeal Life Support; ECMO: Extracorporeal Membrane Oxygenation; HT III: Hypothermia degree III; HT IV: Hypothermia degree IV; LVEF: Left Ventricular Ejection Fraction; OR: Odds Ratio; ROSC: Return of Spontaneous Circulation; VA-ECMO: Veno-Arterial Extracorporeal Membrane Oxygenation; VTI: Velocity Time Integral}

\section{Acknowledgements}

Not applicable.

\section{Authors' contributions}

All authors wrote, read and approved the final manuscript.

\section{Funding}

Not applicable.

\section{Availability of data and materials}

The datasets used and/or analysed during the current study are available from the corresponding author on reasonable request.

Ethics approval and consent to participate

Not applicable.

\section{Consent for publication}

Not applicable.

\section{Competing interests}

The authors declare that they have no competing interests.

Received: 26 November 2019 Accepted: 13 April 2020

Published online: 21 April 2020

\section{References}

1. Durrer B, Brugger H, Syme D. The medical on-site treatment of hypothermia: ICARMEDCOM recommendation. High Alt Med Biol. 2003;4: 99-103.

2. Truhlár A, Deakin CD, Soar J, Khalifa GE, Alfonzo A, Bierens JJ, et al. CardiaC arrest in special circumstances section collaborators. European resuscitation council guidelines for resuscitation 2015: section 4. Cardiac arrest in special circumstances. Resuscitation. 2015;95:148-201.

3. Paal P, Gordon L, Strapazzon G, Brodmann Maeder M, Putzer G, Walpoth B, et al. Accidental hypothermia-an update: The content of this review is endorsed by the International Commission for Mountain Emergency Medicine (ICAR MEDCOM). Scand J Trauma Resusc Emerg Med. 2016;24:111.

4. Mattu A, Brady WJ, Perron AD. Electrocardiographic manifestations of hypothermia. Am J Emerg Med. 2002;20:314-26.

5. Chhabra L, Devadoss R, Liti B, Spodick DH. Electrocardiographic changes in hypothermia: a review. Ther Hypothermia Temp Manag. 2013;3:54-62.

6. Mallet ML. Pathophysiology of accidental hypothermia. QJM. 2002;95:775-85

7. Danzl DF. Accidental hypothermia. Wilderness Medicine. 6th ed. Philadelphia: Elsevier Mosby; 2012. p. 116-42.

8. Althaus U, Aeberhard P, Schüpbach P, Nachbur BH, Mülhemann W. Management of profound accidental hypothermia with cardiorespiratory arrest. Ann Surg. 1982;195:492-5.

9. Ruttmann E, Weissenbacher A, Ulmer H, Müller L, Höfer D, Kilo J, et al. Prolonged extracorporeal membrane oxygenation-assisted support provides improved survival in hypothermic patients with cardiocirculatory arrest. J Thorac Cardiovasc Surg. 2007;134:594-600.

10. Kosiński S, Darocha T, Jarosz A, Czerw A, Podsiadło P, Sanak T, et al. Difficulties in funding of VA-ECMO therapy for patients with severe accidental hypothermia. Anaesthesiol Intensive Ther. 2017;49:106-9.

11. Mair P, Kornberger E, Furtwaengler W, Balogh D, Antretter H. Prognostic markers in patients with severe accidental hypothermia and cardiocirculatory arrest. Resuscitation. 1994:27:47-54

12. Pasquier M, Hugli $O$, Paal $P$, Darocha $T$, Blancher M, Husby $P$, et al. Hypothermia outcome prediction after extracorporeal life support for hypothermic cardiac arrest patients: the HOPE score. Resuscitation. 2018;126: 58-64.

13. Saczkowski RS, Brown DJA, Abu-Laban RB, Fradet G, Schulze CJ, Kuzak ND. Prediction and risk stratification of survival in accidental hypothermia requiring extracorporeal life support: an individual patient data metaanalysis. Resuscitation. 2018;127:51-7.

14. Tveita T, Ytrehus K, Myhre ES, Hevrøy O. Left ventricular dysfunction following rewarming from experimental hypothermia. J Appl Physiol. 1998; 85:2135-9.

15. Loppnow $G$, Wilson LD. Effects of ethanol on systemic hemodynamics in a porcine model of accidental hypothermia. Am J Emerg Med. 2015;33:1414-9.

16. Darocha T, Sobczyk D, Kosiński S, Jarosz A, Gałązkowski R, Nycz K, et al. New diastolic cardiomyopathy in patients with severe accidental hypothermia after ECMO rewarming: a case-series observational study. Cardiovasc Ultrasound. 2015;13:31

17. Enomoto S, Hindman BJ, Dexter F, Smith T, Cutkomp J. Rapid rewarming causes an increase in the cerebral metabolic rate for oxygen that is temporarily unmatched by cerebral blood flow. A study during cardiopulmonary bypass in rabbits. Anesthesiology. 1996;84:1392-400.

18. Gordan ML, Kellermann K, Blobner M, Nollert G, Kochs EF, Jungwirth B. Fast rewarming after deep hypothermic circulatory arrest in rats impairs 
histologic outcome and increases NFKB expression in the brain. Perfusion. 2010;25:349-54.

19. Wanscher M, Agersnap L, Ravn J, Yndgaard S, Nielsen JF, Danielsen ER, et al. Outcome of accidental hypothermia with or without circulatory arrest: experience from the Danish Præstø Fjord boating accident. Resuscitation. 2012;83:1078-84

20. Frei C, Darocha T, Debaty G, Dami F, Blancher M, Carron PN, et al. Clinical characteristics and outcomes of witnessed hypothermic cardiac arrest: a systematic review on rescue collapse. Resuscitation. 2019;137:41-8.

21. McCullough JN, Zhang N, Reich DL, Juvonen TS, Klein JJ, Spielvogel D, et al. Cerebral metabolic suppression during hypothermic circulatory arrest in humans. Ann Thorac Surg. 1999;67:1895-9 discussion 1919-21.

22. Dobson JA, Burgess JJ. Resuscitation of severe hypothermia by extracorporeal rewarming in a child. J Trauma. 1996;3:483-5.

23. Locher T, Walpoth B. Differential diagnosis of circulatory failure in hypothermic avalanche victims: retrospective analysis of 32 avalanche accidents. Praxis. 1996;85:1275-82.

24. Van der Ploeg GJ, Goslings JC, Walpoth BH, Bierens JJ. Accidental hypothermia: rewarming treatments, complications and outcomes from one university medical Centre. Resuscitation. 2010;81:1550-5.

25. Mazur P, Kosiński S, Podsiadło P, Jarosz A, Przybylski R, Litiwnowicz R, et al. Extracorporeal membrane oxygenation for accidental deep hypothermia — current challenges and future perspectives. Ann Cardiothorac Surg. 2019:8:137-42.

\section{Publisher's Note}

Springer Nature remains neutral with regard to jurisdictional claims in published maps and institutional affiliations.

Ready to submit your research? Choose BMC and benefit from:

- fast, convenient online submission

- thorough peer review by experienced researchers in your field

- rapid publication on acceptance

- support for research data, including large and complex data types

- gold Open Access which fosters wider collaboration and increased citations

- maximum visibility for your research: over $100 \mathrm{M}$ website views per year

At $\mathrm{BMC}$, research is always in progress.

Learn more biomedcentral.com/submissions 